Whittaker, E. (2015), 'Inside the snow globe: Pragmatisms, belief and the ambiguous objectivity of the imaginary', Technoetic Arts: A Journal of Speculative Research, 13: 3, pp. 275-284, doi: 10.1386/tear.13.3.275_1

\title{
Inside the snow globe: Pragmatisms, belief and the ambiguous objectivity of the imaginary
}

\author{
Keywords \\ locative narrative apps \\ binaural sound \\ The Lost Index \\ intentionality \\ pragmatism \\ William James \\ multi-stability \\ perceptual ambiguity
}

\begin{abstract}
Relations between perceiving and knowing are well-worn problems that become visceral encounters with doubt and ambiguity in 'mixed-reality' environments. Locative narrative situates participants within stories where existent places function as the setting. Experiential confusion, between what is talked of as real and as imagined, is an often-reported phenomenon. Classical pragmatisms, and more broadly the writings of William James, understand the functioning of the body to be for the production of action, from which flows a naturalistic epistemology. For James, a thought's reference to an object occurs in the medium of an 'experienceable environment' and is a condition of it being known; what something is known-as is how it functions in a particular context and the consequences that follow. Contemporary pragmatists express varying positions on the function of representation in perception at different levels of cognitive awareness, and the extent to which intentionality is derivative of linguistic norms. In the locative narrative iOS application The Lost Index No.1 - Landscape with Figures strategies of directing participant attention, movement, cognitive tasks and propositional content are used to guide the interpretation of events. The complex environment that is created plays with the multi-stability of perception and the 'multi-stability meaning' between terms, resulting in ambiguity and an enhanced flexibility of interpretation.
\end{abstract}

\section{[Page 276]}

The phone rings ... Listen we haven't got long, you need to hear this ... sometime ago you were a volunteer in an experiment to become a human hard-drive ... information was stored in your memory ... while you have no recollection of this event the material now needs to be retrieved ... it is a painless procedure ... For the good of others and yourself, follow these instructions ... You make your way to a gallery on the first floor. You stand in the corner of the room and look down at your phone. First you notice your image reflected on the screen, and then another face emerges. Looking up, you are standing in front of a landscape painting. The voice on the phone again ... 'You are going on a journey' ... your gaze is directed from the gilt frame to the foreground ... You are on the path. A dog barks at your feet ... geese fly low towards the river ... other travelers walking ahead ... passing 
onwards and arriving at the entrance to the church you twist the handle and enter the tower ... The heavy door closes behind you .... Eyes adjusting to the dim interior, you begin to climb ... You reach a room ... On the floor there's a box ... You lift the lid and reach inside ... 'What do you find?' There seems to be something else ... Retracing your journey through the landscape you come to the frame and come back into the gallery. You are back in the gallery. Looking at the phone screen you are prompted to input the data retrieved from your memory.
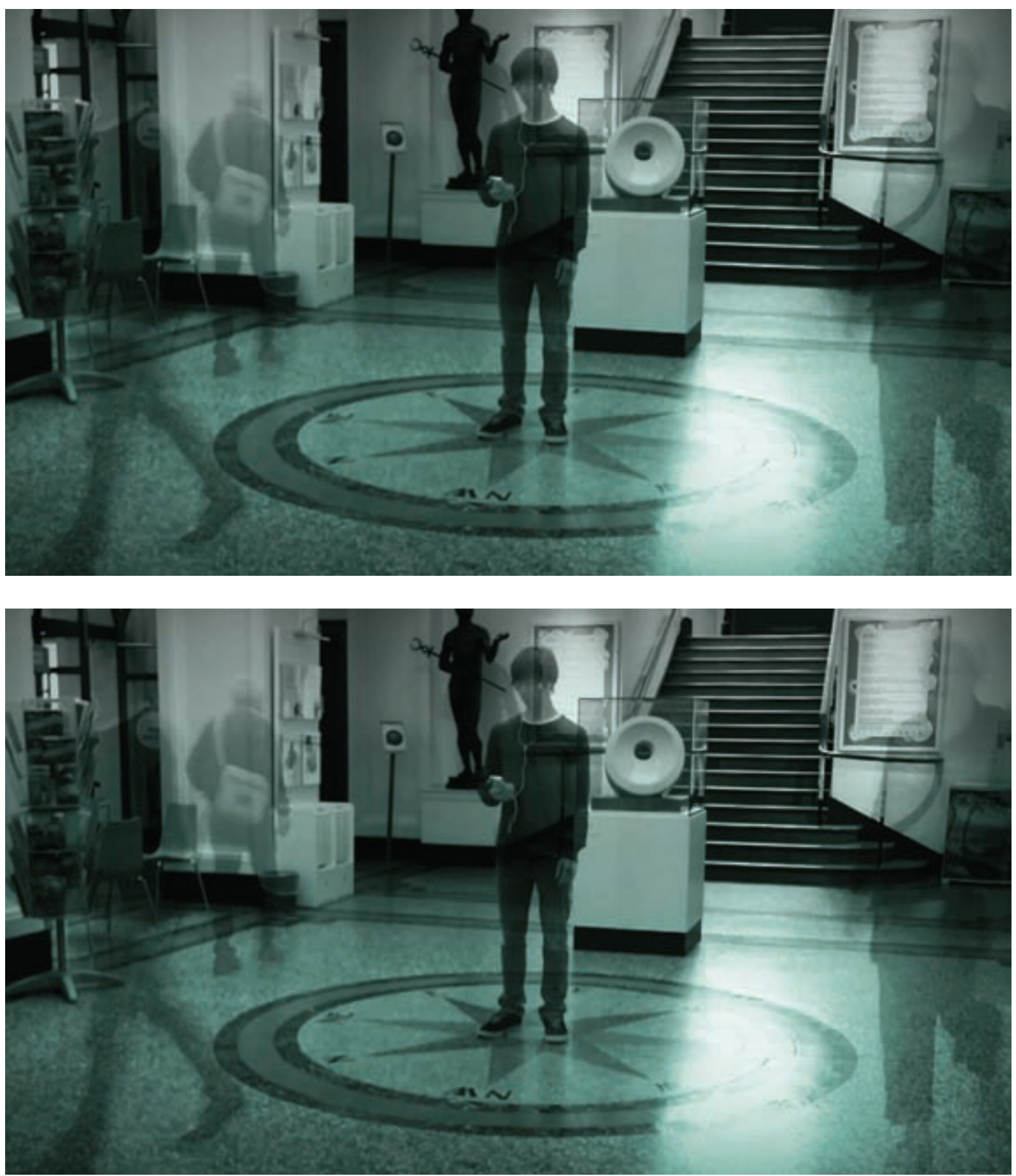

Figure 1: Whittaker, E. \& Brocklehurst, J. R. (2013), 'The Lost Index No.1. - Landscape with Figures, Version 1.0' [iOS Application]. 
[page 277 original article]

In Descartes' Meditations on First Philosophy ([1641] 2008: AT 1: 19) the narrator starts from a position of doubt: Am I dreaming? In the distance the tower is certainly round but approaching he sees that it is square. A piece of wax held in the hand has definite qualities, yet next to the fire its shape and fragrance are altered. How can we trust our senses when things have different 'modes' of appearing? ([1641] 2008: AT 2: 32) Immediately felt sensations, he states, cause nerves to travel through the body to the brain that are represented as 'ideas' to the mind. While we believe our ideas correspond to the world they are often in error. Whereas the intellect apprehends ideas, such as mathematics and geometry as true, independent of the thinker. Descartes concludes that the mind is of a distinctly different nature to the body.

From Descartes' dualism is the view that our perceptions are representative and misrepresentive of the world, and that the content of hallucinations, and that of veridical perception, is a mind-dependent, subjective experience of reality. These positions, often categorized as 'The Argument from Illusion', rest upon, A. D. Smith (2002: 16) argues, an erroneous identity claim - that the content of perception and the content of subjective experience are identical.

Existent objects are not literally what is in our head, and empirical science tends to frame the 'transformation' from sensory stimuli to perception in terms of an intervening representation consistent with the Cartesian dualist 'idea', or the later Russellian 'sense data' (Russell 1910: 181). In recent neuroscience research in auditory perception, Denham and Winkler (2015: 601) find that associations (below the level of awareness) are formed over time, between incoming sounds and persistent 'mental representations'. Multiple sounds heard concurrently are distinguished by patterns of features, 'schema' that are associated with types of sound sources. However, they argue that (2012: 79) perception is not necessarily a stable state. In auditory streaming experiments switching between interpretations can occur when listening to sequences of pure tones. This phenomenon known as multi-stability, is analogous with the experience of ambiguous figures such as the Necker cube or Rubin vase. Its function is posited as a flexible responsiveness to changing environmental conditions.

John Searle's (1983: 18) direct realist theory of perception both breaks from and offers continuity with empirical science. His stance differs from the disjunctivist position, which states that there is nothing in common between veridical perception and hallucinations, holding that both have subjective intentional content (what thoughts are about). In Searle's account objective objects cause perceptual experiences and their subjective content, in this sense, perceptual experiences are 'casually self-reflexive' (2015: 5, 22). A naturalistic account of perceptual processes involves representation between the brain's objective tracking of the environment and subjective reporting on the experience. In this way of talking, perception is a representation. For Searle (2015: 19) existent objects directly cause objective perception, ('world-to-mind' 'direction of fit'), and cause the subjective reference to the experience itself - its intentional content ('mind-to-world' 'direction of fit'). Intentionality has the propositional content of the perception. The propositional content of 
intentional states, such as beliefs and desires, may or may not 'match' with the world. The conditions under which matching is 'satisfied' occurs in relation to the context of a 'Network' $(2015: 12,36)$ of existent beliefs and desires and 'Background abilities'. To see the pen as a rollerball, and believe it writes well, requires a 'Network' of existent ideas and 'Background abilities' for intentionality to be satisfied. Searle $(2015: 74,90)$ takes 'all perception' to be a presentation of a particular instance of an object: the paper on the desk can appear white and in the afternoon yellow. Illusions, he says after Wittgenstein ([1958] 1989: Part II, xi, 194e), are 'seeing-as', a way of talking about a particular [page 278 original article] presentation of an object.

Pragmatist Huw Price (2004: 78) argues that object naturalism rests on the assumption that there is a significant "word-world" semantic relation'. He (2004: 75) rejects the idea that perceptual experience can give us immediate and unprivileged access to 'facts', 'data' or knowledge of the world, on the grounds that our experience is mediated at various levels of neurocognitive processes, within and outside of our awareness. The sense of self and thinking occurs within sociocultural public language, and the 'placement' of objects, as objective or subjective, is not determined by immediate access to (Sellar's) 'the given', but by 'linguistic behaviour'. Robert Brandom $(2011$ : 12, 26) does not see a conflict with scientific explanations of representation that are 'subpersonal' - cognitive processes that occur beneath the level of awareness. He distinguishes between these 'causal' representations and those of 'practical' intentionality - abilities that are skill-based adaptations to the environment, which are implicit in 'discursive' intentionality 'normative' rule-based representations with propositional content that occur at the 'personal' level. The association between meaning and terms in natural language is subject to its use.

The classical pragmatism (and radical empiricism) of William James (1912: 141) does not take immediate experience to be unmediated ${ }^{1}$ or for terms to have fixed interpretations, ${ }^{2}$ rejecting the notion that there is an unqualified correspondence with the world. James also does not abandon 'ordinary' ways of talking; rather he seeks to specify discussion of particular perceptions and conceptions according to how they function in particular contexts. For Price (1998: 241) deflationary accounts are themselves subject to linguistic norms.

James takes 'immediate acquaintance' (1909: 47) with objects, while not unmediated, to yield perceptual knowledge, however, most knowledge is about, and known only symbolically or present in our thoughts intentionally (as intentional content) - a thought of

\footnotetext{
1 “I, for my part, cannot escape the consideration, forced upon me at every turn, that the knower is not simply a mirror floating with no foothold anywhere, and passively reflecting an order that he comes upon and finds simply existing. The knower is an actor, and coefficient of the truth on one side, while on the other he registers the truth which he helps to create." (James [1878] 1920: 67)
}

2 "[...] subjectivity and objectivity are affairs not of what an experience is aboriginally made of, but of its classification. Classifications depend on our temporary purposes [...]" ( James [1912] 1922: 141) 
the Eiffel Tower is present in the absence of the object, after what Brentano refers to as 'intentional inexistence' (1909: 44). To know is the potential to utter propositions that are true of the Eiffel Tower. Mental 'pointing' towards the concept, through a sequence thoughts and their motor consequences, that if carried out that would 'lead harmoniously' (1909: 115) - be incorporated into existing beliefs - and ultimately arrive at an ideal or real context and the immediate presence of the tower. How can the contents of thoughts be explained by pointing towards an idea without already containing the idea? James responds by differentiating between knowing that is verified and knowing that is in transit. He says that we are 'virtual knowers' (1912: 68), before we arrive outside the tower and point at it. However, we may never visit. Our thought may never get beyond the virtual stage for us. Our thoughts may have other mental or physical substitutes that lead us to other ideas or practical outcomes (1909: 110). Both types of knowing occur in the medium of a specific 'experienceable environment' (1909: 41). We know things by the practical effects they have on the world. We can say an object is 'known-as' real because it functions as a real pen, while some ideas have a 'reality-feeling' despite being vague or 'almost unimaginable' (1902: 58).

That our experience can give us direct access to objective objects rather than normative ways of talking about objects is a point of contention between pragmatists (Hildebrand 2014: 7) [page 279 original article]. James says we do not know to what degree concepts affect perception and to what extent perceptions affect concepts.

The universal and the particular parts of the experience are literally immersed in each other, and both are indispensable. (1911: 107) The potential for interpretation to ride on the wave crest $^{3}$ or to be pulled beneath the surface and reconfigured, simulated, counterfactually conjured and novel, is arguably the very unfixity and 'flowing over' that natural language offers, (even within Wittgenstein's [2009: xi 347] constraints of general agreement). An analogous and perhaps reciprocal relationship can be talked of between the multi-stability of meaning between terms and that of perceptual multi-stability, the reporting of appearances that appear to switch between interpretations of the same stimuli under the same conditions.

The pen lying on the table in the next room doesn't mark this paper. Thoughts or movements towards it are 'ambulatory' ([1878] 1920: 60) relations; they occur in-action, in the space and time that separates my concept from its terminus, the existent pen I pick up. My perception 'hangs' off my concept in 'a concatenated or continuous structure' (1909: xii-xiii) of concrete transitions. Picking it up and pressing down, it functions for me. However, my daydream of the Eiffel Tower pen I once owned only functions in the domain of my thoughts. I tip it up and tiny snow falls slowly in its miniature snowglobe world. Scooping up the snow, I hurl it against the glass. Looking down, the page is blank. Many times our thoughts are not terminated; they remain in transit, flowing towards their next effects.

3 'We live, as it were, upon the front edge of an advancing wavecrest, and our sense of a determinate direction in falling forward is all we cover of the future of our path' (James 1912: 69). 
Locative narrative can be defined as storied audio experiences that take the form of games or drama. Heard on headphones and set in 'real world' locations, the participant moves simultaneously in the physical and the fictional place. The confluence of ambient and recorded sound, the seen and the described and the observed and performed, can lead to perceptual ambiguity and shifts in perspective. Experiential confusion between the existent and the imagined is an often-reported feature of these 'mixed-reality' (Milgram and Kishino 1994) environments. Montola et al. (2009 xxi) describe the spatial, temporal and social expansion of pervasive game worlds that blur boundaries, extending the concept of the 'magic circle' derived from game theorists Salen and Zimmerman (2004) and Johan Huizinga (1955 [1938]). Reid et al. (2005: 209) describe 'synthetic confusion' and heightened experience of these 'magic moments'. Benford et al. (2006: 435) discuss 'blurring the frame' as a strategy for repositioning behaviours and emotional responses in fictional and real worlds, drawing upon Gregory Bateson (1972) and Erving Goffman (1974).

Introduced at the top of the paper, the science fiction locative narrative The Lost Index No1: Landscape with Figures (2013) is a guided imaginary experience in binaural sound, set in Plymouth City Museum and Art Gallery ${ }^{4}$ and accessed via headphones and an iOS app.

The participant encounters a number of intersecting contexts. The existent museum is the place where the experience takes place. Launching the app and donning headphones signals that it is 'non-serious', in Searle's (1975: 320) terms. The graphical interface declares the science fiction genre. Fictional places are intersecting and nested: the museum is recast as a covert location of unknown agents; the phone rings, a voice emits from an unspecified office; a [page 281 original article] landscape depicted in a painting is the setting for the action, moving beyond the visual depiction, the interior of church tower is represented in sound.

James (1890b: 293) says that we assign objects in our experience to different categories or 'worlds': the physical world of heat, colour, sound; the worlds of scientific laws; of mathematics, logic, ethics, aesthetics; of common beliefs and prejudices; of supernatural beliefs, religion or fictions; of individual opinion; or of madness or vagary. Our categorization, immediate or delayed, is dependent upon our current perspective and point of view. A fact we may label as fiction can operate as true within a proposition or an imagined scenario. The imagining of a horse with wings works in the context of the legend of Pegasus but not in relation to the existent horse living in the stable. Wings are true in relation to the particular world to which they refer.

The participant has varying relations to these contexts. The sociocultural mores and behaviourial norms of the museum are reassigned by the expectations of game play. Answering the phone, listening and following directions are enacted as part of the story. Simply walking through the museum becomes a performance.

Recorded sound, movement and attention-focusing techniques mediate participants' relations to the environmental and narrative contexts. Vocal suggestions encourage

\footnotetext{
${ }^{4}$ Landscape with Figures c. 1650 Salomon van Ruysdael.
} 
concentration on the face appearing on the phone screen and guide the imaginative 'transition' into the world of the painting. In the present tense, with minimal description, simple sentences address the listener in the second person, drawing upon structure of hypnotic inductions (Weitzenhoffer and Hilgard 1999). Binaural sound naturalistically depicts the traversing of people and animals within the landscape painting that surrounds Figure 2: Whittaker, E. \& Brocklehurst, J. R. (2013), 'The Lost Index No.1. - Landscape with Figures, Version 1.0' [iOS Application] the listener. While attention is focused on the narrative or the painting, thoughts of incongruity with the gallery may be deferred. What we take to be veridical or describe as imaginary can be vague or distinct. When slippages of relations to context occur, what is talked of as real and as imagined may become ambiguous or confused. Objective and subjective spaces flip and interpenetrate, but the imagined will not function in the real world.

'I took my earphones out, I just couldn't work out where the sound of the baby was coming from'. 'It really felt like I was being watched'. 'I heard footsteps coming up behind me and thought there was someone there'.
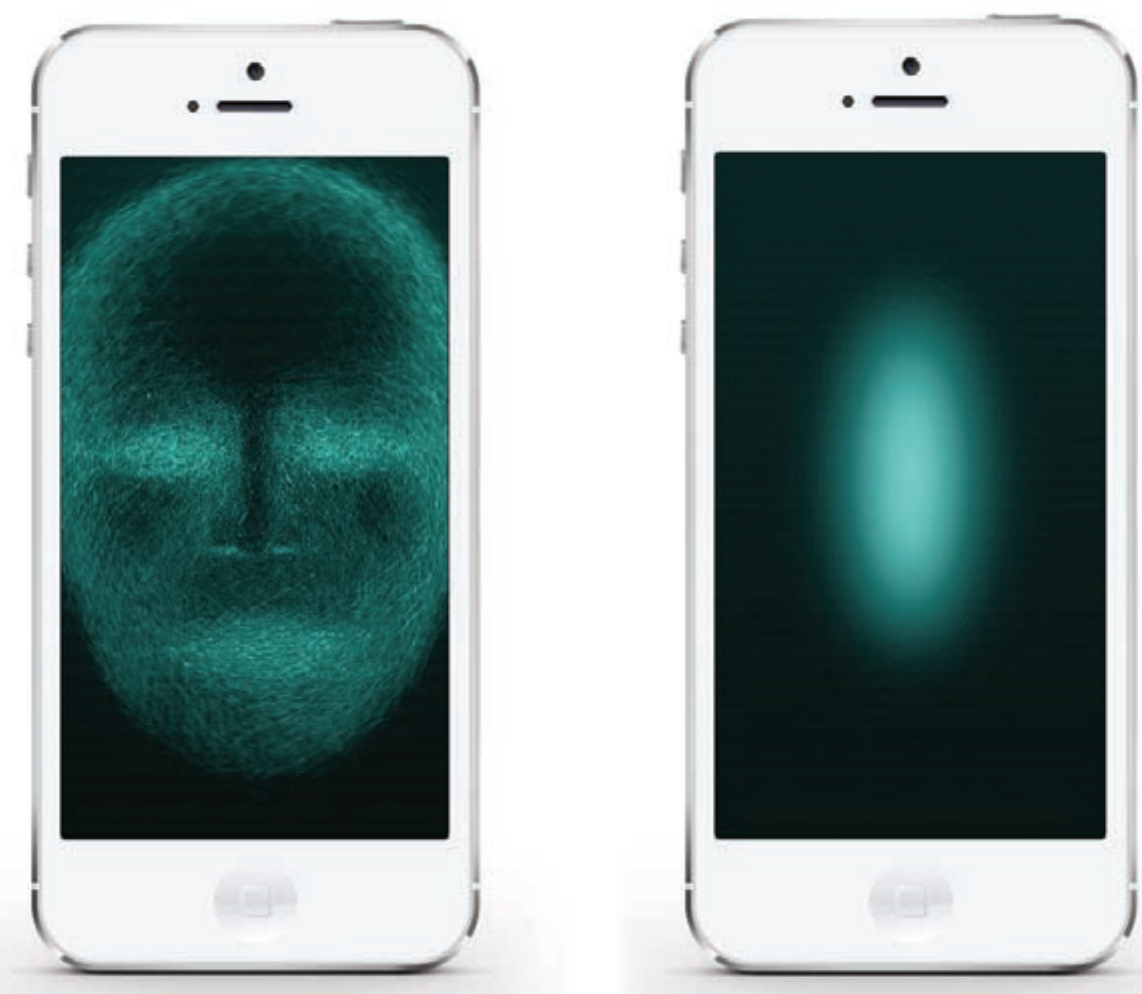

Figure 2: Whittaker, E. \& Brocklehurst, J. R. (2013), 'The Lost Index No.1. Landscape with Figures', Version 1.0' [iOS Application].

Some facts are true only within the story, that you are a 'human drive', that there exists a church interior, box and contents, but they are also potential actually imagined events. James' assertion that beliefs occur in-action allows for the movement between these contexts to be fluid. Experientially worlds are nested within one another with truth-values 
varyingly assigned. It is our particular contextual relation to these spaces that affects whether we take them to be real or imagined.

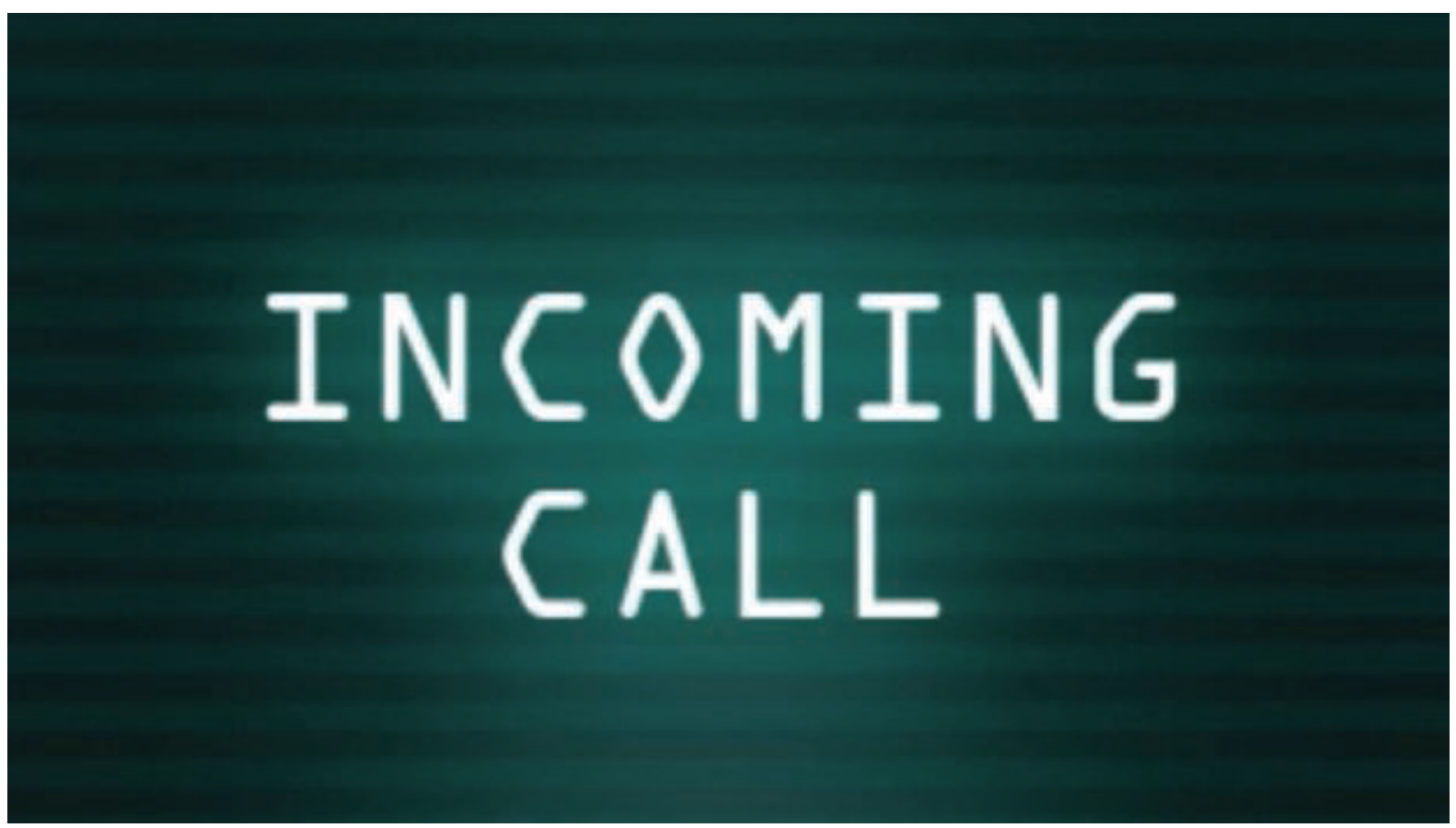

Figure 3: Whittaker, E. \& Brocklehurst, J. R. (2013), 'The Lost Index No.1. Landscape with Figures, Version 1.0' [iOS Application].

The painting has a dual function as a theatrical prop within the narrative and as an aidememoire in the memory game, that functions as 'magical' object rather than a literal doorway to the outdoors. To enter the tower requires departing from the surface of the painting; only sounds depict the imaginary interior. Events preceding the present moment frame the experience as a story. Truth is a value in experience. Our beliefs about the world are mostly unverified but hang together in a concatenated structure, from one to another occurring in-action.

\section{Conclusion}

The experienceable environment of locative narrative plays with the multistability of meaning between terms, in a reciprocal adoption of the vocabulary of perceptual multistability. Directing and misdirecting attention, steering emotion and guiding interpretation can defer classification of fictional places, as real or imagined, keeping knowing in transit.

[page 282 original article]

\section{Acknowledgements}

Grateful thanks to Adam Milford and Lisa Mitchell of Plymouth City Museum and Art Gallery, who kindly facilitated access and gave their support to the The Lost Index iOS collection of apps.

\section{References}

Bateson, G. (1972), Steps to an Ecology of Mind, Northvale, New Jersey: Jason 
Aronson Inc.

Benford, S., Crabtree, A., Reeves, S., Flintham, M., Drozd, A., Sheridan, J., Dix, A. (2006), 'The frame of the game: Blurring the boundary between fiction and reality in mobile experiences', $\mathrm{CHI}$ 2006, Montréal, Québec, Canada, 22-27 April.

Brandom, R. (2011), Perspectives in Pragmatism, Classical, Recent and Contemporary, Massachusetts: Harvard University Press.

Bregman, A. S. ([1990] 1994), Auditory Scene Analysis: The Perceptual Organization of Sound, Cambridge, MA: MIT Press.

Denham, S. and Winkler, I. (2015), 'Auditory perceptual organization', in J. Wagemans (ed.), The Oxford Handbook of Perceptual Organisation, Oxford: Oxford University Press, p. 601.

Denham, S., Bendixen, A., Mill, R., Tóth, D., Wennekers, T., Coath, M., Böhm, T. Szalardy, O., Winkler, I. (2012), 'Characterising switching behaviour in perceptual multi-stability', Journal of Neuroscience Methods, 210: 1, pp. 79-92, dx.doi.org/10.1016/j.jneumeth.2012.04.004. Accessed 20 November 2015.

Descartes, R. ([1641] 2008), Meditations on First Philosophy (trans. Michael Moriarty), Oxford: Oxford University Press, pp. AT 1: 19.

Goffman, E. (1974), Frame Analysis, New York: Harper Colophon.

Hildebrand, D. M. (ed.) (2014), 'Symposia. language or experience: Charting pragmatism's course for the 21st century', European Journal of Pragmatism and American Philosophy, 6: 2, pp. 6-13.

Huizinga, J. (1955 [1938]), Homo Ludens: A Study of the Play Element in Culture, Boston: Beacon Books.

James, W. ([1878] 1920), 'Remarks on spencer's mind as correspondence', in W. James (ed.), Collected Essays and Reviews, New York: Longman, Green and Co., p. 60.

- - (1890a), The Principles of Psychology, vol. 1, New York: Henry Holt and Company.

- - (1890b), The Principles of Psychology, vol. 2, New York: Henry Holt and Company.

- (1897), Will to Believe, New York: Longmans, Green \& Company.

- - (1902), The Varieties of Religious Experience, A Study in Human Nature, New York: Longmans, Green \& Company. 
- - (1907), Pragmatism, New York: Longmans, Green \& Company.

- - (1909), The Meaning of Truth, New York: Longmans, Green \&

Company.

- - (1911), Some Problems of Philosophy, New York: Longmans, Green \&

Company.

- - ([1912] 1922), Essays in Radical Empiricism, New York: Longman, Green

and Co., p. 141.

Milgram, P. and Kishino, F. (1994), 'Taxonomy of mixed reality visual displays', IEICE Transactions on Information and Systems, E77-D:12, December, http://etclab.mie.utoronto.ca/people/paul_dir/IEICE94/ieice.html. Accessed 20 November 2015.

[page 283 original article]

Montola, M., Stenros, J. and Waern, A. (2009), Pervasive Games, Theory \& Design, Burlington: Morgan Kaufmann.

Price, H. (1998), 'Three norms of assertibility, or how the Moa became extinct'. Noûs, 32: S12, pp. 241-54.

- - (2004), 'Naturalism without representationalism', in David Macarthur and Mario de Caro (eds) (2008), Naturalism in Question, New York: Harvard University Press, pp. 71-88.

Reid, J., Hull, R., Cater, K. and Fleuriot, C. (2005), 'Magic moments in situated mediascapes', ACE 2005, ACM SIGCHI, Valencia, Spain, 15-17 June. pp. 290-293.

Russell, B. (1910), Philosophical Essays, London: Longmans, Green and Co., p. 181.

Salen, K. \& Zimmerman, E. (2003), A Rules of Play: Game Design Fundamentals, Mass.: MIT.

Searle, J. R. (1975), 'The logical status of fictional discourse new literary history', 6: 2, On Narrative and Narratives, Winter, pp. 319-32, http://www. jstor.org/stable/468422.

- - (1983), Intentionality, Cambridge: Cambridge University Press.

- - (2015), Seeing Things as They Are, A Theory of Perception, Oxford: Oxford University Press.

Smith, A. D. (2002), The Problem of Perception, London: Palgrave, p. 16.

Whittaker, E. and Brocklehurst, J. R. (2013), The Lost Index No.1. - Landscape with Figures, Version 1.0 (iOS Application), Apple Inc., https://itunes. apple.com/us/app/lost-index-no.1landscape/id730623803?mt=8. Accessed 20 November 2015. 
Weitzenhoffer, A. M. and Hilgard, E. R. (1999), Stanford Hypnotic Susceptibility Scale: Forms $C$ (Modified by John F. Kihlstrom), Palo Alto: Stanford University Press.

Wittgenstein, L. (2009 [1958]), Philosophical Investigations, 4th Edition (trans. G. E. M. Anscombe, P. M. S. Hacker and Joachim Hacker), Chichester: Wiley-Blackwell, pp. xi, 194e.

\section{Suggested Citation}

Whittaker, E. (2015), 'Inside the snow globe: Pragmatisms, belief and the ambiguous objectivity of the imaginary', Technoetic Arts: A Journal of Speculative Research, 13: 3, pp. 275-284, doi: 10.1386/tear.13.3.275_1

\section{Contributor Details}

Emma Whittaker is an artist and researcher of locative narrative. She investigates transformation of existent environments with imagined locations using smartphone and sensor technologies. Recent collaborative projects include the iOS apps The Lost Index, No.1: Landscape with Figures (2013), The Lost Index, No.2: The Turning (2014) nominated for a Media Innovation Award, LociOscope, The Letters (2014) and The Lost Index: NATMUS, National Museum of Denmark, Copenhagen (2015). Her research explores fictional places and perceptual experience, drawing upon the vocabularies of classical pragmatism and the writings of William James. Emma Whittaker co-directs Trulylmagined with James Brocklehurst. She convenes the Expanded Narrative Research Network and is a member of the Art and Sound Research Group. She is a collaborator with the Marie Curie-funded CogNovo Doctoral Research Centre and an associate lecturer in Media Arts at Plymouth University.

\section{Contact:}

Emma Whittaker, School of Art \& Media, Plymouth University, Plymouth, PL4 8AA, UK.

\section{Websites:}

www.trulyimagined.org; www.expandednarrative.org; www.plymouth.ac.uk/staff/ewhittaker

Emma Whittaker has asserted her right under the Copyright, Designs and Patents Act, 1988, to be identified as the author of this work in the format that was submitted to Intellect Ltd. 